\title{
Role of rostral ventrolateral medullary ERK/JNK/p38 MAPK signaling in the pressor effects of ethanol and its oxidative product acetaldehyde
}

\author{
Mahmoud M. El-Mas, Ming Fan, and Abdel A. Abdel-Rahman \\ Department of Pharmacology and Toxicology, School of Medicine, East Carolina University, \\ Greenville, North Carolina, U.S.A.
}

\section{Abstract}

\begin{abstract}
Background-We tested the hypothesis that alterations of the phosphorylation/ dephosphorylation profile of mitogen-activated protein kinases (MAPKs) in the rostral ventrolateral medulla (RVLM) underlies the pressor response elicited by ethanol microinjection into the RVLM of spontaneously hypertensive rats (SHRs). The studies were extended to determine if acetaldehyde (ACA), the primary oxidative product of ethanol, replicates the molecular effects of ethanol within the RVLM and the consequent pressor response.
\end{abstract}

Methods-Effects of ethanol or ACA on blood pressure (BP) were evaluated in the absence or presence of selective JNK (SP600125), ERK (PD98059), p38 (SB203580), or ser/thr phosphatases (okadaic acid, OKA) inhibitor.

Results-Intra-RVLM ethanol (10 $\mu \mathrm{g} / \mathrm{rat})$ or ACA ( $2 \mu \mathrm{g} / \mathrm{rat})$ caused a similar ERK2-dependent pressor response because ethanol or ACA-evoked increases in BP and in RVLM p-ERK2 level were abolished after pharmacologic inhibition of ERK phosphorylation. SP600125 abrogated the pressor action of ethanol, but not ACA, thus implicating JNK in ethanol action on BP. Despite ethanol enhancement of $\mathrm{p} 38$ phosphorylation, pharmacological studies argued against a causal role for this kinase in ethanol-evoked pressor response. RVLM phosphatase catalytic activity was not influenced by ethanol or ACA. Interestingly, pharmacologic phosphatase inhibition (OKA), which increased RVLM p-ERK2 and BP, abrogated the pressor effect of subsequently administered ethanol or ACA.

Conclusions-Enhancement of RVLM ERK2 phosphorylation constitutes a major molecular mechanism for the pressor response elicited by intra-RVLM ethanol or its metabolite, ACA, in conscious SHRs. Further, RVLM kinases dephosphorylation does not contribute to intra-RVLM ethanol- or ACA-evoked pressor response.

\section{Keywords}

Ethanol; acetaldehyde; hypertension; mitogen activated protein kinases; spontaneously hypertensive rats

Author for correspondence: Abdel A. Abdel-Rahman, Ph.D., Department of Pharmacology, School of Medicine, East Carolina University, Greenville, NC 27834. Tel. (252)744-3470; Fax (252)744-3203; abdelrahmana @ecu.edu.

Dr. Mahmoud M. El-Mas is on a sabbatical leave from the Department of Pharmacology, Faculty of Pharmacy, Alexandria University, Egypt (mahelm@hotmail.com). 


\section{Introduction}

The RVLM is the brainstem neuronal pool from which bulbospinal sympathetic neurons descend to the intermediolateral cell column of the spinal cord (Chalmers and Pilowsky, 1991). Our recent cardiovascular and electrochemical studies suggested a key role for RVLM neurons in the sympathoexcitatory and pressor responses elicited by ethanol in conscious SHRs (Li et al., 2005; Mao et al., 2003). Intra-RVLM ethanol produced dosedependent increases in RVLM norepinephrine electrochemical signal and BP in SHRs in contrast to no effects in WKY rats (Li et al., 2005). Since the activity of norepinephrinecontaining neurons in the RVLM is proportionally related to the sympathetic neural activity (Bhaskaran and Freed, 1989), we proposed and established a crucial role for these neurons in the pressor action of ethanol in SHRs (Li et al., 2005). Notably, other contributing mechanisms to the pressor action of ethanol include impairment of arterial baroreflex activity (El-Mas and Abdel-Rahman, 1993a,b; 1998), increased intracellular calcium (Yang et al., 2001), and oxidative stress (Husain et al., 2011; Soardo et al., 2008).

MAPKs are a group of serine/threonine kinases that convert extracellular stimuli into a wide range of cellular responses (Cargnello and Roux, 2011; English and Cobb, 2002). Conventional MAPKs comprise the extracellular signal-regulated kinases (ERK1/2), c-Jun amino (N)-terminal kinases (JNK1/2/3), and p38 (Cargnello and Roux, 2011). MAPKs have been implicated in many actions of ethanol such as hepatotoxicity, pancreatitis, neurotoxicity and increased cancer risk (Aroor and Shukla, 2004; Kalluri and Ticku, 2003). Ethanol may upregulate or downregulate the phosphorylation of MAPKs depending on the experimental settings including duration and dose of exposure, cell type, and MAPK isoform under investigation (Aroor and Shukla, 2004). Studies in vascular preparations showed that ethanol-induced contractions and elevation of intracellular calcium in smooth muscle cells are mediated through the activation of ERK1/2 and p38 (Yang et al., 2001), and ethanol-evoked contraction of isolated aortas is suppressed by MEK1/2 inhibition (Yang et al., 2002). Further, it has been demonstrated that the inhibition of RVLM ERK1/2lowers BP and attenuates the pressor response caused by angiotensin II microinjection into the same neuronal pool (Seyedabadi et al., 2001). In spite of the critical role of the RVLM in the pressor response of ethanol in SHRs, and the importance of RVLM MAPKs signaling in blood pressure control, no reports are available on the potential involvement of MAPKs in the pressor action of intra-RVLM ethanol.

In the present study, we tested the hypothesis that enhanced phosphorylation of MAPKs (ERK1/2, p38 and/or JNK) contributes to the pressor effect of intra-RVLM ethanol in conscious SHRs. We also determined if ACA contributed, at least partly, to the molecular and BP effects of intra-RVLM ethanol. Notably, the principal ethanol metabolic product, ACA, mediates some of the behavioral effects of ethanol (Karahanian et al., 2011; Pastor and Aragon, 2008). Further, we have recently demonstrated a key role for the local enzymatically (catalase)-produced ACA in the pressor action of intra-RVLM ethanol in SHRs (El-Mas and Abdel-Rahman, 2012). Accordingly, we conducted integrative and exvivo studies to investigate the effect of intra-RVLM ethanol or ACA on BP in absence or presence of a selective pharmacologic inhibitor of ERK, p38, or JNK. Two more experimental approaches were adopted to elucidate a potential causal role for MAPK(s) activation in the pressor action of intra-RVLM ethanol or ACA. First, we determined the influence of intra-RVLM ethanol or ACA on the phosphorylation (activation) of the investigated MAPK isoforms. Second, we utilized biochemical and pharmacologic approaches to investigate the possibility that ethanol or ACA increased ERK1/2 phosphorylation and consequently BP by inhibiting the activity of RVLM serine/threonine phosphatases; the latter deactivate MAPKs via dephosphorylation (Cargnello and Roux, 2011). The integrative studies were conducted in conscious animals to circumvent potential 
confounding effects of anesthetics on MAPK and BP responses cause by ethanol or acetaldehyde in the absence or presence of the MAPK inhibitors used in the study.

\section{Materials and methods}

Male SHRs (12-13 weeks old, Charles River, Raleigh, NC) were used. Surgical procedures and post-operative care were performed in accordance with, and approved by, the Institutional Animal Care and Use Committee and in accordance with the Guide for the Care and Use of Laboratory Animals as adopted and promulgated by the U.S. National Institutes of Health.

\section{Intracranial cannulation}

The method described in our previous studies was employed (El-Mas and Abdel-Rahman, 2012; Li et al., 2005; Nassar et al., 2011). Briefly, rats were anesthetized with i.p. ketamine $(90 \mathrm{mg} / \mathrm{Kg})$ and xylazine $(10 \mathrm{mg} / \mathrm{Kg})$ and supplemented as needed. Rats were mounted in the prone position in a cranial stereotaxic apparatus (David Kopf Instruments, Tujunga, CA). A steel guide cannula (23G, Small Parts, Miami, FL) was implanted intracranially so that its tip was positioned $2 \mathrm{~mm}$ above the RVLM using the interaural line as the reference and the following coordinates: posterior $-2.8 \mathrm{~mm}$, lateral $\pm 2.0 \mathrm{~mm}$, and dorsoventral $\pm 0.5 \mathrm{~mm}$. The cannula was secured in place with small metal screws and dental acrylic cement (Durelon, Thompson Dental Supply, Raleigh, NC). Each rat received i.m buprenorphine $(30 \mu \mathrm{g} / \mathrm{kg})$ and s.c. Durapen (penicillin G benzathine and penicillin $\mathrm{G}$ procaine in an aqueous suspension, 100,000 $\mathrm{U} / \mathrm{kg}$ ) and housed in a separate cage.

\section{Intravascular cannulation}

Three days after intracranial cannulation, catheters (each consisting of $5 \mathrm{~cm}$ polyethylene-10 tubing bonded to $15 \mathrm{~cm}$ polyethylene-50 tubing) filled with heparinized saline (100 units/ $\mathrm{ml}$ ) were placed in the abdominal aorta via the left femoral artery for measurement of BP as in our previous studies (El-Mas and Abdel-Rahman, 1999; El-Mas et al., 1997a,b; 2003).

\section{Cardiovascular measurements}

Five days after intracranial cannulation, BP was measured by connecting the arterial catheter to a Gould-Statham pressure transducer (Oxnard, CA, U.S.A.) and BP was displayed on a PowerLab system (ADInstruments, Inc., Colorado, USA) as previously described (El-Mas et al., 2011a, 2011b; Nassar et al., 2011). A 30-gauge microinjector, connected to a $0.5 \mu 1$ Hamilton syringe, was inserted into the guide cannula with its tip located in the RVLM. The accurate placement of the injector was verified by chemical and histological means as in reported studies including ours (El-Mas and Abdel-Rahman, 2012; Li et al., 2005). Chemical identification was made at the beginning of the experiment by observing the pressor response after microinjection of $1 \mathrm{nmol}$ of L-glutamate ( $40 \mathrm{nl})$. Histologically, $40 \mathrm{nl}$ of fast green dye (1\%) was delivered at the end of the experiment to mark the injection site. Frozen coronal sections $(40 \mu \mathrm{m})$ were cut and examined for the injection site using the atlas of Paxinos and Watson (1986).

\section{Western blotting}

For the measurement of intra-RVLM MAPKs protein expressions (total and phosphorylated) in SHRs treated with ethanol, acetaldehyde or their vehicle (artificial cerebrospinal fluid, ACSF), micropunches were taken from the RVLM of frozen brains with a stainless steel bore (i.d. $0.94 \mathrm{~mm}$, Stoelting Co, Wood Dale, IL) as reported in previous studies including ours (Bardgett et al., 2010; Nassar et al., 2011). Tissues were sonicated on ice in a homogenization buffer [20 mM Tris (pH 7.5), $150 \mathrm{mM} \mathrm{NaCl}, 1 \mathrm{mM}$ EGTA, $1 \mathrm{mM}$ EDTA, 
1\% Triton $\mathrm{X}-100,2.5 \mathrm{mM}$ sodium pyrophosphate, $1 \mathrm{mM} \beta$-glycerol phosphate, $1 \mathrm{mM}$ sodium orthovanadate, $0.1 \%$ leupeptin] using sonic dismembrator (Thermo Fisher Scientific INC). After quantification of protein with Bio-Rad protein assay system, $5 \mu \mathrm{g}$ of protein extract per lane were run on a 4-12\% SDS-PAGE gel (Invitrogen, CA) and electroblotted to nitrocellulose membranes. Blots were blocked for $2 \mathrm{hr}$ at room temperature in Odyssey blocking buffer (LI-COR Biosciences, Lincoln, NE). They were then incubated overnight at $4^{\circ} \mathrm{C}$ in Odyssey blocking buffer with mouse antibodies to phospho-p44/42 MAPK (ERK1/2) (Thr202/Tyr204) (1:1000), phosphor-SAPK/JNK (Thr183/Tyr185) (1:1000), phospho-p38 MAPK (Thr180/Tyr182) (1:500), or rabbit antibodies to p44/42 MAPK (ERK1/2) (1:1500), SAPK/JNK (1:1000), p38 MAPK (1:500) (Cell Signaling Technology, INC. Danvers, Massachusetts). After 3 washes with PBS-T buffer, the blots were incubated for 50 min at room temperature with a goat anti-mouse secondary antibody IRDye ${ }^{\circledR} 800 \mathrm{CW}$ or a goat anti-rabbit secondary antibody IRDye ${ }^{\circledR} 680 \mathrm{CW}$ (LI-COR Biosciences, Lincoln, NE). After 3 washes with PBS-T buffer, the blots were detected by Odyssey Infrared Scanning System. At the end, membranes were stripped and probed for rabbit GAPDH antibody (1:5000, Cell Signaling Technology, INC. Danvers, Massachusetts) in accordance with the incubation and washing procedure described above. Protein bands were quantified by integrated intensities using Odyssey Infrared Imaging Software, which serve as good surrogates for the relative express levels of targeting proteins (Nassar et al., 2011). The phospho-protein was normalized to the corresponding total protein in the same sample and results were then expressed as percent of control (ACSF)

\section{Measurement of phosphatase activity}

Phosphatase activity was measured colorimetrically in $10 \mu \mathrm{g}$ protein using the Ser/Thr Phosphatase Assay Kit 1 (Malachite Green Assay, Upstate Cell Signaling Solutions, Lake Placid, NY) according to the manufacturer's instructions.

\section{Experimental protocols}

\section{Effect of intra-RVLM ethanol or ACA on phosphorylated kinase levels and the catalytic activity of phosphatase activity in the RVLM}

This series of studies was conducted in SHRs because our previous studies demonstrated that the pressor response elicited by intra-RVLM ethanol was not evident in Wistar Kyoto rats under the same conditions (El-Mas and Abdel-Rahman, 2012; Li et al., 2005). In this experiment, we tested the hypothesis that intra-RVLM ethanol or ACA increased the level of phosphorylated ERK1, ERK2, JNK and p38, at least partly via the inhibition of phosphatase enzymatic activity in RVLM neurons. Therefore, at the conclusion of the integrative studies, detailed below, the rats that received ethanol, ACA or ACSF were euthanized with an overdose of pentobarbital sodium $(100 \mathrm{mg} / \mathrm{kg})$ and their brains were rapidly removed and stored at $-80^{\circ} \mathrm{C}$ until used for Western blot and phosphatase enzymatic activity as detailed above. Further, we investigated the effect of local phosphatase inhibition on the phosphorylated state of the aforementioned MAPKs in following intra-RVLM okadaic acid $(0.4 \mu \mathrm{g})$. The BP responses elicited by ethanol or ACA in this experiment ( $n=6-8$ /group) prior to tissue collection were compared with the cardiovascular responses observed following pharmacologic MAPKs inhibition in the RVLM (see below).

\section{Influence of local inhibition of MAPKs or phosphatase on the cardiovascular effects of intra-RVLM ethanol or acetaldehyde}

In this experiment, we investigated the effects of selective pharmacologic inhibition of RVLM JNK (SP600125), p38 (SB203580), ERK1/2 (PD98059), or serine/threonine phosphatases (okadaic acid, OKA), on the cardiovascular responses elicited by intra-RVLM ethanol or acetaldehyde. The dose of intra-RVLM SP600125 (1 $\mu \mathrm{g})$, SB203580 (0.5 $\mu \mathrm{g})$, 
PD98059 $(1 \mu \mathrm{g})$ or OKA $(0.4 \mu \mathrm{g})$ was selected based on reported studies (Choe et al., 2004; Gerdjikov et al., 2004). A total of 15 groups of conscious SHRs ( $\mathrm{n}=6-8$ each), preinstrumented with intra-arterial and intra-RVLM cannulas as detailed earlier, were used. A period of at least $60 \mathrm{~min}$ was allowed at the beginning of each experiment for BP stabilization. All injections ( $40 \mathrm{nl}$ ) were made unilaterally into the RVLM according to established protocol in our lab (El-Mas and Abdel-Rahman, 2012; Li et al., 2005). Control rats received DMSO, the vehicle for the pharmacologic inhibitors, followed by ACSF to control for ethanol/acetaldehyde microinjection. Treatment groups received one of the inhibitors or the vehicle followed 30 min later by ethanol $(10 \mu \mathrm{g})$, acetaldehyde $(2 \mu \mathrm{g})$ or ACSF. These doses of ethanol and acetaldehyde produce similar pressor (El-Mas and AbdelRahman, 2012; Li et al., 2005) and neurobiological effects (Quertemont et al., 2005). To establish dose-effect relationships for acetaldehyde, the blood pressure and heart rate responses elicited by 1 and $4 \mu \mathrm{g}$ intra-RVLM doses of acetaldehyde were investigated in two separate groups of rats $(n=6-8)$. Blood pressure and heart rate were monitored for $60 \mathrm{~min}$ following the intra-RVLM ethanol, acetaldehyde or ACSF.

\section{Drugs}

Ketaject (ketamine), Xyla-ject (xylazine) (Phoenix Pharmaceuticals Inc., St Joseph, MI), buprenorphine (Rickitt \& Colman, Richmond, VA), Durapen (Vedco Inc., Overland Park, KS), SP600125 [anthra[1,9-cd]pyrazol-6(2H)-one], SB203580 [4-[4-(4-fluorophenyl)-2-(4methylsulfinylphenyl)-1 $H$-imidazol-5-yl]pyridine], PD98059 [2-(2-Amino-3methoxyphenyl)-4H-1-benzopyran-4-one], okadaic acid, acetaldehyde (Sigma Chemical Co., St. Louis, MO), ethanol (Midwest Grain Products Co., Weston, MO) were purchased from commercial vendors.

\section{Statistical analysis}

Values are expressed as means \pm S.E.M. Mean arterial pressure (MAP) was computed via integration of the area under the pulse pressure curve using the LabChart software. The analysis of variance (ANOVA) followed by a Newman-Keuls post-hoc analysis was used

\section{Results}

As shown in Table 1, baseline MAP values in all rat groups prior to drug or vehicle administration were not statistically different.

\section{Intra-RVLM ethanol or acetaldehyde causes similar (ERK1/2) and differential (JNK and p38) enhancements of kinase phosphorylation in the RVLM neurons}

Intra-RVLM ethanol or acetaldehyde caused significant $(\mathrm{p}<0.05)$ activation (phosphorylation) of ERK2 (p-ERK2, Fig. 1A) and JNK2/3 (p-JNK2/3; Fig. 1B), compared with corresponding ACSF values. By contrast, neither ethanol nor acetaldehyde affected the RVLM levels of p-ERK1 (Fig. 1A) or p-JNK1 (Fig. 1B). p38 phosphorylation was significantly $(\mathrm{p}<0.05)$ increased by ethanol but not by acetaldehyde (Fig. 1C). The enzyme catalytic activity of RVLM serine/threonine phosphatase was similar in the rats that received intra-RVLM ethanol, acetaldehyde or ACSF $(1.59 \pm 0.29,1.11 \pm 0.42$, and $1.37 \pm 0.37 \mu \mathrm{mol} /$ $\mathrm{min} / \mathrm{mg}$ protein) indicating lack of RVLM phosphatases action (dephosphorylation) in the net effect of ethanol or acetaldehyde on the phosphorylation state of the investigated kinases. 


\section{Pharmacological evidence for common and differential involvement of RVLM MAPKs activation in the pressor effect of intra-RVLM ethanol or acetaldehyde}

Figures 2-5 illustrate the influence of selective inhibition of RVLM MAPKs on BP and HR responses elicited by subsequent intra-RVLM ethanol or acetaldehyde in conscious SHRs. The intra-RVLM administration of SP600125 $(1 \mu \mathrm{g})$ or SB203580 $(0.5 \mu \mathrm{g})$ caused significant $(\mathrm{p}<0.05)$ reductions in the RVLM protein expression of p-JNK-1 (Fig. 2B) and p38 (Fig. 2C), respectively. On the other hand, the protein expression of p-ERK1/2 in the RVLM neurons was apparently reduced in rats treated with PD98059 $(1 \mu \mathrm{g})$; however, the reduction approached but did not achieve statistical significance when compared to control values (Fig. 2A). Compared with corresponding vehicle (ACSF) values, intra-RVLM ethanol $(10 \mu \mathrm{g})$ caused significant increases in MAP, which continued for the 60-min observation period (Fig. 3A). The pressor effect of ethanol was replicated, both in magnitude and duration, by intra-RVLM $2 \mu \mathrm{g}$ acetaldehyde (Fig. 3C). Selective inhibition of RVLM JNK by SP600125 (1 $\mu \mathrm{g})$, which caused no significant changes in baseline MAP, virtually abolished the pressor effect of intra-RVLM ethanol (Fig. 3A) and slightly attenuated the pressor response elicited by intra-RVLM acetaldehyde (Fig. 3C).

Selective inhibition of p38 (SB203580; $0.5 \mu \mathrm{g}$ ) or ERK1/2 (PD98059; $1 \mu \mathrm{g}$ ) phosphorylation had no effect on baseline MAP, compared with corresponding vehicle (DMSO) values, but they variably affected the pressor response elicited by intra-RVLM ethanol or acetaldehyde. In SB203580-pretreated rats, the pressor effect of intra-RVLM ethanol or acetaldehyde was still evident but was delayed in onset (Fig. 4A, C). This contrasts with the effect of the MEK inhibitor PD98059, which virtually abolished the pressor action of both ethanol (Fig. 5A) and acetaldehyde (Fig. 5C). Unlike MAP, no changes in HR were demonstrated after intraRVLM administration of ethanol/acetaldehyde, inhibitors of MAPKs, or their combinations (Figs. 3-5, bottom panels).

Compared with corresponding DMSO values, the inhibition of RVLM phosphatase activity by OKA $(0.4 \mu \mathrm{g})$ significantly increased the phosphorylated ERK2 level (Fig. 6A). The expressions of other proteins were not affected by OKA (Fig. 6B, C). Further, BP was increased by OKA, which achieved statistical significance, compared with corresponding DMSO values, at $30 \mathrm{~min}$ and thereafter (Fig. 7A). In OKA-pretreated SHRs, subsequent intra-RVLM ethanol (Fig. 7A) or acetaldehyde (Fig. 7C) increased MAP to levels that were similar to those produced by OKA alone.

Figure 8 describes the dose-hemodynamic effect relationships for intra-RVLM acetaldehyde. At the dose levels of 1 and $2 \mu \mathrm{g}$, acetaldehyde caused dose-related increases in MAP but had no effect on HR (Fig. 8). The $4 \mu \mathrm{g}$ dose of acetaldehyde elevated MAP to levels similar to those caused by the $2 \mu \mathrm{g}$ dose (Fig. 8A); however, the pressor response elicited by the $4 \mu \mathrm{g}$ dose was associated with significant $(\mathrm{p}<0.05)$ reductions in $\mathrm{HR}$ at 50 and 60 min (Fig. 8B).

\section{Discussion}

The present study is the first report on the role of RVLM MAPKs in the pressor response elicited by intra-RVLM microinjection of ethanol or its main metabolite, acetaldehyde, in SHRs. The pressor response elicited by intra-RVLM ethanol or acetaldehyde coincided with increased ERK2 phosphorylation in the RVLM. Inhibition of RVLM ERK (PD98059) abrogated the pressor action of intra-RVLM ethanol or acetaldehyde. The data also selectively implicate JNK2/3 in the pressor effect of ethanol because (i) the inhibition of JNK (SP600125) abolished the pressor effect of ethanol but not acetaldehyde, and (ii) ethanol significantly increased the RVLM JNK2/3 phosphorylation. Finally, biochemical (phosphatase activity) and pharmacological (phosphatase inhibition) findings rule out a role 
for RVLM phosphatase in the higher phosphorylated state of the implicated kinases and the consequent pressor response elicited by ethanol or acetaldehyde.

We hypothesized that ethanol acting directly or indirectly via its metabolite acetaldehyde elevates BP, at least partly, via activation of MAPKs within RVLM neurons. This premise was based on reported evidence that (i) implicated activation of RVLM ERK1/2 and p38 in the higher sympathetic activity in stroke-prone SHRs (Kishi et al., 2010) and in heart failure (Gao et al., 2010), and (ii) intra-RVLM acetaldehyde reproduced the pressor effect of ethanol (El-Mas and Abdel-Rahman, 2012). Limiting ethanol or acetaldehyde action to the RVLM made it feasible to investigate the role of the studied kinases in this neuronal pool in the pressor response. We demonstrated significant increases in local ERK2 phosphorylation caused by intra-RVLM ethanol. Equally important, we showed that prior RVLM ERK1/2 inhibition (PD98059) virtually abolished the ethanol-evoked pressor response. Together, these novel molecular and pharmacological findings support a causal role for enhanced ERK2 phosphorylation in the pressor effect of intra-RVLM ethanol.

While our finding on ethanol activation of RVLM ERK2 is consistent with findings in other tissues, studies on the effect of ethanol on p38 and JNK signaling produced conflicting data. It was imperative, therefore, to pharmacologically confirm whether the molecular response was causally linked to the pressor responses elicited by ethanol; this approach was followed with ERK1/2 as discussed above. Based on this strategy, the increase in the RVLM p-p38 level in does not seem to contribute to ethanol-evoked pressor response because the latter was preserved after pharmacological inhibition of p38 (SB203580). On the other hand, despite the lack of change of neuronal p-JNK in ethanol-treated SHRs, JNK inhibition (SP600125) compromised the pressor effect of ethanol. While these findings preclude a direct interaction of ethanol with JNK, the possibility exists that ethanol modulation of one or more of the downstream effectors of JNK signaling, e.g. the immediate early gene c-jun and/or the transcription factor activator protein-1 (AP-1) (Choi et al., 2009; Yeligar et al., 2009), might contribute to the evoked pressor response. Interestingly, a causal link exists between increases in c-Jun or its message, c-jun, in the RVLM and sympathetic activity (ElMas and Abdel-Rahman 2000; Wang et al., 2005).

We investigated the possibility that inhibition of RVLM phosphatases contributed to the net increases in ERK1/2 phosphorylation, which as discussed above played a causal role in the pressor effect of ethanol. This premise was based on the neurochemical function of the serine/threonine phosphatases, which dephosphorylate MAPKs (Cargnello and Roux, 2011; Roth Flach and Bennett, 2010). Our finding that ethanol or its metabolite acetaldehyde (see below) had no effect on RVLM phosphatase activity argued against such possibility. We then hypothesized that local phosphatase inhibition (OKA) could exacerbate the pressor response elicited by ethanol for two reasons. First, inhibition of phosphatase activity in cell culture contributes to ethanol-evoked increase in p-JNK level (Meriin et al., 1999). Second, enhanced MAPKs signaling in the RVLM increases sympathetic activity (Gao et al., 2010; Kishi et al., 2010). While our efforts to gain pharmacological support for our hypothesis were hampered by the increased BP caused by intra-RVLM OKA, the latter finding yielded new neurobiologically relevant information. Indeed, the OKA-evoked pressor response (Fig. 7) and concomitant elevations in p-ERK2 (Fig. 6) suggest that the RVLM phosphatases serve to limit the buildup of neuronal phosphorylated MAPKs, which enhance sympathetic activity (Gao et al., 2010; Kishi et al., 2010). Collectively, the current increases in BP and RVLM p-ERK2 that followed OKA lend credence to our overall conclusion that higher levels of phosphorylated kinases in the RVLM mediate, at least partly, the pressor response caused by intra-RVLM ethanol. In fact, the increase in BP caused by intra-RVLM OKA, may have circumvented additional BP increases by subsequent ethanol administration. This 
possibility may be supported by the relatively limited BP responses caused by intra-RVLM administration of pharmacological interventions in our present study.

The metabolic breakdown of ethanol involves its oxidation to acetaldehyde via multiple enzymatic pathways including alcohol dehydrogenase or catalase (Quertemont et al., 2005). Some (Karahanian et al., 2011; Pastor and Aragon, 2008) but not all studies (Quertemont, 2003; Quertemont et al., 2005) emphasized the importance of acetaldehyde in mediating behavioral effects of ethanol. It was important, therefore, to investigate whether intraRVLM acetaldehyde replicates the molecular and cardiovascular effects of ethanol. We found that, similar to ethanol, acetaldehyde (i) increased RVLM p-ERK2 levels, (ii) caused pERK1/2- but not p38-dependent elevation in BP, and (iii) had no effect on phosphatase activity. Notably, one clear difference between ethanol and acetaldehyde was the dependence of ethanol-evoked pressor response on enhanced RVLM JNK2/3 phosphorylation. Thus, it is possible that while enhancement of JNK2/3 and ERK2 phosphorylation underlie ethanol-evoked pressor response, ERK2 phosphorylation plays the major role in the pressor action of acetaldehyde. Nonetheless, these findings support a critical role for acetaldehyde in the molecular and cardiovascular effects of ethanol. Further, our molecular findings are consistent with a pivotal role for enhanced RVLM ERK1/2 signaling in mediating increases in sympathetic activity and BP because activation of RVLM angiotensin $\mathrm{AT}_{1} \mathrm{R}$ triggers ERK-dependent sympathoexcitation in hypertensive rats (Kishi et al., 2010), and inhibition of RVLM ERK1/2lowers BP and attenuates the pressor response caused by intra-RVLV angiotensin II (Seyedabadi et al., 2001).

Our finding that MAPKs differentially contributed to the pressor response elicited by ethanol (ERK2 and JNK2/3) and acetaldehyde (ERK2) deserves a comment. It is tempting to speculate that the JNK2/3 and ERK2 might constitute two consecutive signaling events in the cellular pathway involved in the acetaldehyde-dependent pressor effect of ethanol, with the phosphorylation of JNK2/3 leading to downstream ERK activation. Along the same cascade, recent evidence suggests a facilitatory role for alcohol dehydrogenase in the ethanol-evoked JNK phosphorylation (Oh et al., 2008) in addition to its established role in ethanol metabolism (Quertemont et al., 2005). Notably, the oxidative catabolism of ethanol into acetaldehyde by alcohol dehydrogenase/catalase mediates the pressor action of intraRVLM ethanol in SHRs (El-Mas and Abdel-Rahman, 2012). Unlike ethanol, the pressor effect of acetaldehyde involved the direct activation of ERK, thereby bypassing JNK and the ethanol metabolic pathway. These cellular mechanisms along with the proposed cascade of neuronal substrates involved in the MAPKs-related pressor effect of ethanol/acetaldehyde reported here and in our previous study (Li et al., 2005) are illustrated in figure 9.

One potential limitation of the present study relates to the possibility that the microinjected ethanol dose into brainstem neurons might have caused neuronal damage and produced nonspecific effects. The microinjected dose of ethanol employed in the current study has been repeatedly used in brainstem microinjection studies in our laboratory (El-Mas and Abdel-Rahman, 1993b; Li et al., 2005) and by others (Varga and Kunos, 1990; 1992) to study the role of discrete brain areas in ethanol hemodynamics. Ethanol microinjection into brainstem nuclei was found to impair arterial baroreflexes via interaction with specific subsets of central GABA and glutamate receptors and these effects disappeared within 1-2 hr (El-Mas and Abdel-Rahman, 1993; Varga and Kunos, 1990). Our findings that RVLM ERK and JNK but not $\mathrm{p} 38$ contributed to pressor effect of ethanol also reflect the discrepant interaction of ethanol with different signaling networks within the RVLM neurons. This selectivity and reversibility made it unlikely that ethanol effects are mediated via nonspecific neuronal damage. With regards to the relevance of the microinjected ethanol dose, it is imperative to note that comparable cardiovascular effects are produced by ethanol administered into the RVLM $(10 \mu \mathrm{g})$ or systemically ( $1 \mathrm{~g} / \mathrm{kg}$ ) (El-Mas and Abdel-Rahman, 
1993a,b; 1998; Varga and Kunos, 1990; 1992). Notably, the $1 \mathrm{~g} / \mathrm{kg}$ dose of ethanol produces blood alcohol levels similar to those attained in humans after consumption of moderate to heavy amounts of alcohol (Abdel-Rahman et al., 1987; Ireland et al., 1984), which reinforces the clinical relevance of the current data.

Given the similarity of the cardiovascular effects produced by systemic ethanol $(1 \mathrm{~g} / \mathrm{kg})$ and microinjected ethanol $(10 \mu \mathrm{g})$ into brainstem nuclei including the RVLM (El-Mas and Abdel-Rahman, 1993a,b; 1998; Varga and Kunos, 1990; 1992), it is plausible that these two ethanol regimens would produce comparable levels of the drug in the RVLM. This assumption receives support from the study by Robinson et al. (2000), which reported similar blood and brain levels of $\sim 25 \mathrm{mM}$ following i.v. administration of the $1 \mathrm{~g} / \mathrm{kg}$ dose of ethanol. Collectively, these findings predict that the $10 \mu \mathrm{g}$ intra-RVLM dose of ethanol used in our studies might lead to tissue ethanol concentration of approximately $25 \mathrm{mM}$, which is consistent with blood levels achieved following social alcohol consumption (Abdel-Rahman et al., 1987; Ireland et al., 1984).

The present study reports a key role for enhanced RVLM-ERK2 signaling in the pressor action of ethanol and acetaldehyde. The findings also support the involvement of RVLM JNK2/3 phosphorylation in the pressor effect of ethanol. Importantly, the activation of the targeted MAPKs within the RVLM occurred via the enhancement of the phosphorylation rather than the dephosphorylation processes because neither ethanol nor acetaldehyde altered the RVLM phosphatase activity. Nonetheless, our intriguing pharmacological and molecular findings with phosphatase inhibition (OKA) support a physiological restraining role for RVLM phosphatases against further increases in BP in the SHR. Given the involvement of MAPK signaling in metabolic disorders including cardiovascular disease (Roth Flach and Bennett, 2010), these kinases and phosphatases could be exploited as therapeutic targets for circumventing ethanol-evoked pressor response and perhaps for the control of hypertension.

\section{Acknowledgments}

The authors thank Kui Sun and Hoda Khafaga for their technical assistance.

This work was supported by the National Institutes of Health National Institute on Alcohol Abuse and Alcoholism [Grant 2R01 AA07839-19].

\section{References}

Abdel-Rahman A-RA, Merrill RH, Wooles WR. Effect of acute ethanol administration on the baroreceptor reflex control of heart rate in normotensive human volunteers. Clin Sci. 1987; 72:113122. [PubMed: 3802717]

Aroor AR, Shukla SD. MAP kinase signaling in diverse effects of ethanol. Life Sci. 2004; 74:23392364. [PubMed: 15027449]

Bardgett ME, McCarthy JJ, Stocker SD. Glutamatergic receptor activation in the rostral ventrolateral medulla mediates the sympathoexcitatory response to hyperinsulinemia. Hypertension. 2010; 55:284-290. [PubMed: 20065145]

Bhaskaran D, Freed CR. Catechol and indole metabolism in rostral ventrolateral medulla change synchronously with changing blood pressure. J Pharmacol Exp Ther. 1989; 249:660-666. [PubMed: 2724147]

Cargnello M, Roux PP. Activation and function of the MAPKs and their substrates, the MAPKactivated protein kinases. Microbiol Mol Biol Rev. 2011; 75:50-83. [PubMed: 21372320]

Chalmers J, Pilowsky P. Brainstem and Bulbospinal neurotransmitter systems in the control of blood pressure. J Hypertens. 1991; 9:675-694. [PubMed: 1680911] 
Choe ES, Parelkar NK, Kim JY, Cho HW, Kang HS, Mao L, Wang JQ. The protein phosphatase 1/2A inhibitor okadaic acid increases CREB and Elk-1 phosphorylation and c-fos expression in the rat striatum in vivo. J Neurochem. 2004; 89:383-390. [PubMed: 15056282]

Choi EY, Hwang HJ, Kim IH, Nam TJ. Protective effects of a polysaccharide from Hizikia fusiformis against ethanol toxicity in rats. Food Chem Toxicol. 2009; 47:134-139. [PubMed: 19026708]

El-Mas MM, Abdel-Galil AAG, El-Gowelli HM, Daabees TT. Short-term aortic barodenervation diminishes $\alpha_{1}$-adrenoceptor reactivity in rat aortic smooth muscle. Eur J Pharmacol. 1997a; 322:201-210. [PubMed: 9098688]

El-Mas MM, Abdel-Rahman AA. Direct evidence for selective involvement of aortic baroreceptors in ethanol-induced impairment of baroreflex control of heart rate. J Pharmacol Exp Ther. 1993a; 264:1198-1205. [PubMed: 8450457]

El-Mas MM, Abdel-Rahman AA. Ovariectomy abolishes ethanol-induced impairment of baroreflex control of heart rate in conscious rats. Eur J Pharmacol. 1998; 349:253-261. [PubMed: 9671105]

El-Mas MM, Abdel-Rahman AA. Estrogen-dependent hypotensive effects of ethanol in conscious female rats. Alcohol Clin Exp Res. 1999; 23:624-632. [PubMed: 10235298]

El-Mas MM, Abdel-Rahman AA. Clonidine diminishes c-jun gene expression in the cardiovascular sensitive areas of the rat brainstem. Brain Res. 2000; 856:245-249. [PubMed: 10677633]

El-Mas MM, Abdel-Rahman AA. Enhanced catabolism to acetaldehyde in rostral ventrolateral medullary neurons accounts for the pressor effect of ethanol in spontaneously hypertensive rats. Am J Physiol Heart Circ Physiol. 2012; 302:H837-H844. [PubMed: 22159996]

El-Mas MM, Abdel-Rahman A-RA. Role of NMDA and non-NMDA receptors in the nucleus tractus solitarius in the depressant effect of ethanol on baroreflexes. J Pharmacol Exp Ther. 1993b; 266:602-610. [PubMed: 8102644]

El-Mas MM, Afify EA, Omar AG, Mohy El-Din MM, Sharabi FM. Testosterone depletion contributes to cyclosporine-induced chronic impairment of acetylcholine renovascular relaxations. Eur J Pharmacol. 2003; 468:217-224. [PubMed: 12754060]

El-Mas MM, Daabees TT, El-Gowelli HM, Abdel-Galil AA. Enhanced endothelial nitric oxide activity contributes to the reduced responsiveness of vascular $\mathrm{a}_{1}$-adrenoceptors following aortic barodenervation. Eur J Pharmacol. 1997b; 337:235-243. [PubMed: 9430420]

El-Mas MM, El-Gowelli HM, Abd-Elrahman KS, Saad EI, Abdel-Galil AG, Abdel-Rahman AA. Pioglitazone abrogates cyclosporine-evoked hypertension via rectifying abnormalities in vascular endothelial function. Biochem Pharmacol. 2011a; 81:526-533. [PubMed: 21114962]

El-Mas MM, El-gowilly SM, Fouda MA, Saad EI. Role of adenosine $\mathrm{A}_{2 \mathrm{~A}}$ receptor signaling in the nicotine-evoked attenuation of reflex cardiac sympathetic control. Toxicol Appl Pharmacol. 2011b; 254:229-237. [PubMed: 21550361]

English JM, Cobb MH. Pharmacological inhibitors of MAPK pathways. Trends Pharmacol Sci. 2002; 23:40-45. [PubMed: 11804650]

Gao L, Li Y, Schultz HD, Wang WZ, Wang W, Finch M, Smith LM, Zucker IH. Downregulated $\mathrm{Kv} 4.3$ expression in the RVLM as a potential mechanism for sympathoexcitation in rats with chronic heart failure. Am J Physiol Heart Circ Physiol. 2010; 298:H945-H955. [PubMed: 20044444]

Gerdjikov TV, Ross GM, Beninger RJ. Place preference induced by nucleus accumbens amphetamine is impaired by antagonists of ERK or p38 MAP kinases in rats. Behav Neurosci. 2004; 118:740 750. [PubMed: 15301601]

Husain K, Ferder L, Ansari RA, Lalla J. Chronic ethanol ingestion induces aortic inflammation/ oxidative endothelial injury and hypertension in rats. Hum Exp Toxicol. 2011; 30:930-939. [PubMed: 20921064]

Ireland MA, Vandongen R, Davidson L, Beilin LJ, Rouse IL. Acute effects of moderate alcohol consumption on blood pressure and plasma catecholamines. Clin Sci. 1984; 66:643-648. [PubMed: 6723203]

Kalluri HS, Ticku MK. Regulation of ERK phosphorylation by ethanol in fetal cortical neurons. Neurochem Res. 2003; 28:765-769. [PubMed: 12716028] 
Karahanian E, Quintanilla ME, Tampier L, Rivera-Meza M, Bustamante D, Gonzalez-Lira V, Morales P, Herrera-Marschitz M, Israel Y. Ethanol as a prodrug: brain metabolism of ethanol mediates its reinforcing effects. Alcohol Clin Exp Res. 2011; 35:606-612. [PubMed: 21332529]

Kishi T, Hirooka Y, Konno S, Ogawa K, Sunagawa K. Angiotensin II type 1 receptor-activated caspase-3 through ras/mitogen-activated protein kinase/extracellular signal-regulated kinase in the rostral ventrolateral medulla is involved in sympathoexcitation in stroke-prone spontaneously hypertensive rats. Hypertension. 2010; 55:291-297. [PubMed: 20065158]

Li G, Wang X, Abdel-Rahman AA. Brainstem norepinephrine neurons mediate ethanol-evoked pressor response but not baroreflex dysfunction. Alcohol Clin Exp Res. 2005; 29:639-647. [PubMed: 15834230]

Mao L, Li G, Abdel-Rahman AA. Effect of ethanol on reductions in norepinephrine electrochemical signal in the rostral ventrolateral medulla and hypotension elicited by $\mathrm{I}_{1}$-receptor activation in spontaneously hypertensive rats. Alcohol Clin Exp Res. 2003; 27:1471-1480. [PubMed: 14506409]

Meriin AB, Yaglom JA, Gabai VL, Zon L, Ganiatsas S, Mosser DD, Zon L, Sherman MY. Proteindamaging stresses activate c-Jun N-terminal kinase via inhibition of its dephosphorylation: a novel pathway controlled by HSP72. Mol Cell Biol. 1999; 19:2547-2555. [PubMed: 10082520]

Nassar N, Li G, Strat A, Abdel-Rahman AA. Enhanced Hemeoxygenase Activity in the Rostral Ventrolateral Medulla Mediates the Exaggerated Hemin-Evoked Hypotension in the SHR. J Pharmacol Exp Ther. 2011; 339:267-274. [PubMed: 21768222]

Oh YI, Kim JH, Kang CW. Effects of ethanol on insulin-like growth factor-I system in primary cultured rat hepatocytes: implications of JNK1/2 and alcoholdehydrogenase. World J Gastroenterol. 2008; 14:4324-4331. [PubMed: 18666320]

Pastor R, Aragon CM. Ethanol injected into the hypothalamic arcuate nucleus induces behavioral stimulation in rats: an effect prevented by catalase inhibition and naltrexone. Behav Pharmacol. 2008; 19:698-705. [PubMed: 18797246]

Paxinos, G.; Watson, C. The Rat Brain in Stereotaxic Coordinates. New York: Academic Press; 1986.

Quertemont E. Discriminative stimulus effects of ethanol with a conditioned taste aversion procedure: lack of acetaldehyde substitution. Behav Pharmacol. 2003; 14:343-350. [PubMed: 12838040]

Quertemont E, Tambour S, Tirelli E. The role of acetaldehyde in the neurobehavioral effects of ethanol: a comprehensive review of animal studies. Prog Neurobiol. 2005; 75:247-274. [PubMed: 15882776]

Robinson DL, Lara JA, Brunner LJ, Gonzales RA. Quantification of ethanol concentrations in the extracellular fluid of the rat brain: in vivo calibration of microdialysis probes. J Neurochem. 2000; 75:1685-1693. [PubMed: 10987851]

Roth Flach RJ, Bennett AM. Mitogen-activated protein kinase phosphatase-1 - a potential therapeutic target in metabolic disease. Expert Opin Ther Targets. 2010; 14:1323-1332. [PubMed: 21058921]

Seyedabadi M, Goodchild AK, Pilowsky PM. Differential role of kinases in brain stem of hypertensive and normotensive rats. Hypertension. 2001; 38:1087-1092. [PubMed: 11711502]

Soardo G, Donnini D, Moretti M, Milocco C, Catena C, Sechi LA. Effects of antihypertensive drugs on alcohol-induced functional responses of cultured human endothelial cells. Hypertens Res. 2008; 31:345-351. [PubMed: 18360055]

Varga K, Kunos G. Ethanol inhibition of baroreflex bradycardia: role of brainstem GABA receptors. Br J Pharmacol. 1990; 101:773-775. [PubMed: 1964817]

Varga K, Kunos G. Inhibition of baroreflex bradycardia by ethanol involves both $\mathrm{GABA}_{\mathrm{A}}$ and GABA $_{B}$ receptors in the brainstem of the rats. Eur J Pharmacol. 1992; 214:223-232. [PubMed: 1325357]

Wang X, Li G, Abdel-Rahman AA. Site-dependent inhibition of neuronal c-jun in the brainstem elicited by imidazoline I1 receptor activation: role in rilmenidine-evoked hypotension. Eur J Pharmacol. 2005; 514:191-199. [PubMed: 15910806]

Yang ZW, Wang J, Zheng T, Altura BT, Altura BM. Ethanol-induced contractions in cerebral arteries: role of tyrosine and mitogen-activated protein kinases. Stroke. 2001; 32:249-257. [PubMed: 11136944] 
Yang ZW, Wang J, Zheng T, Altura BT, Altura BM. Roles of tyrosine kinase-1-phosphatidylinositol 3-kinase-, and mitogen-activated protein kinase-signaling pathways in ethanol-induced contractions of rat aortic smooth muscle: possible relation to alcohol-induced hypertension. Alcohol. 2002; 28:17-28. [PubMed: 12377357]

Yeligar SM, Machida K, Tsukamoto H, Kalra VK. Ethanol augments RANTES/CCL5 expression in rat liver sinusoidal endothelial cells and human endothelial cells via activation of NF-kappa B, HIF-1 alpha, and AP-1. J Immunol. 2009; 18:5964-5976. [PubMed: 19828633] 

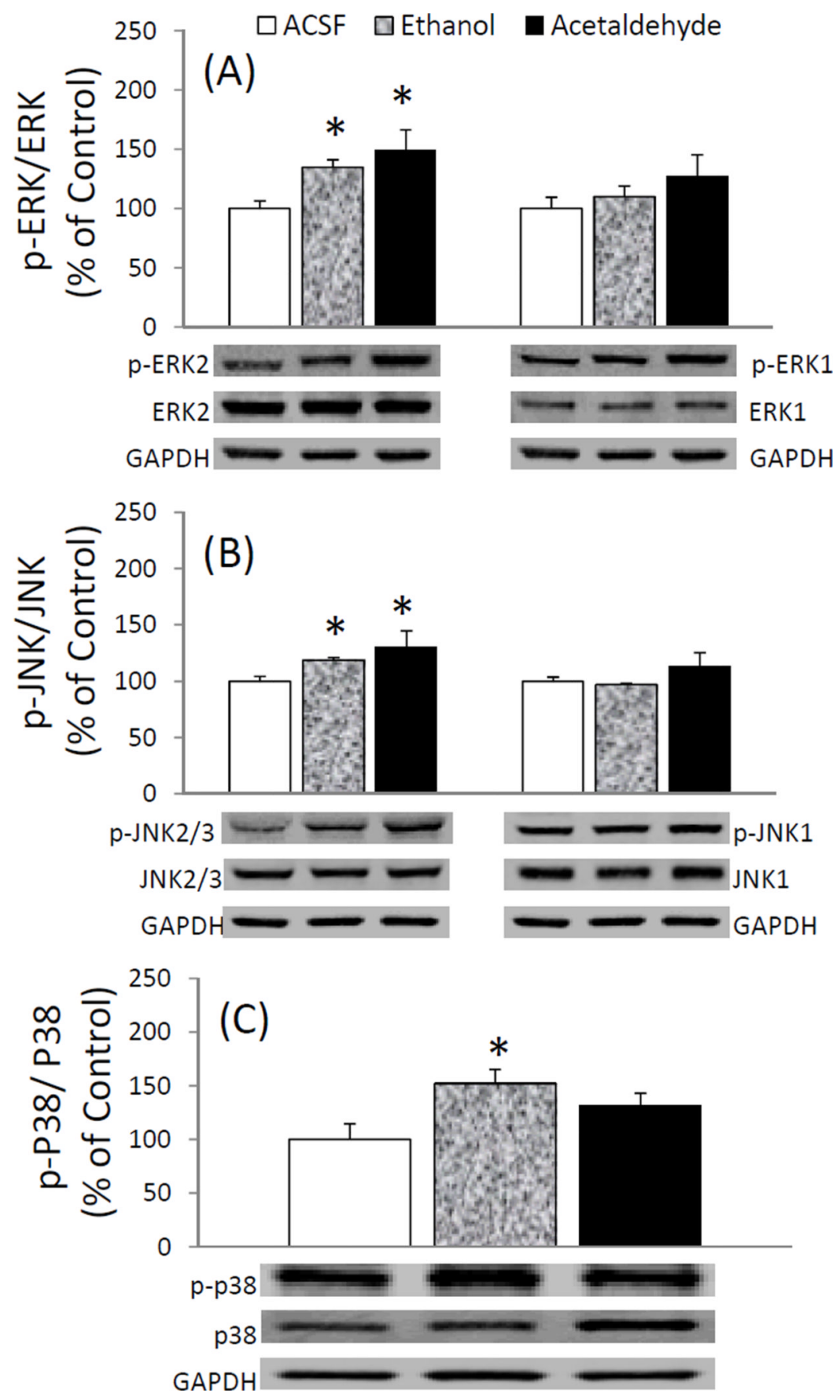

Figure 1.

The protein expressions of ERK1/2, JNK1/JNK2/3, and p38 in the RVLM of SHRs treated with ethanol $(10 \mu \mathrm{g})$, acetaldehyde $(2 \mu \mathrm{g})$, or equal volume of ACSF. Illustrative gels depicting the expression of these proteins are shown. Values are means \pm S.E.M of 6-7 observations. ${ }^{*} \mathrm{P}<0.05$ versus corresponding ACSF values. 

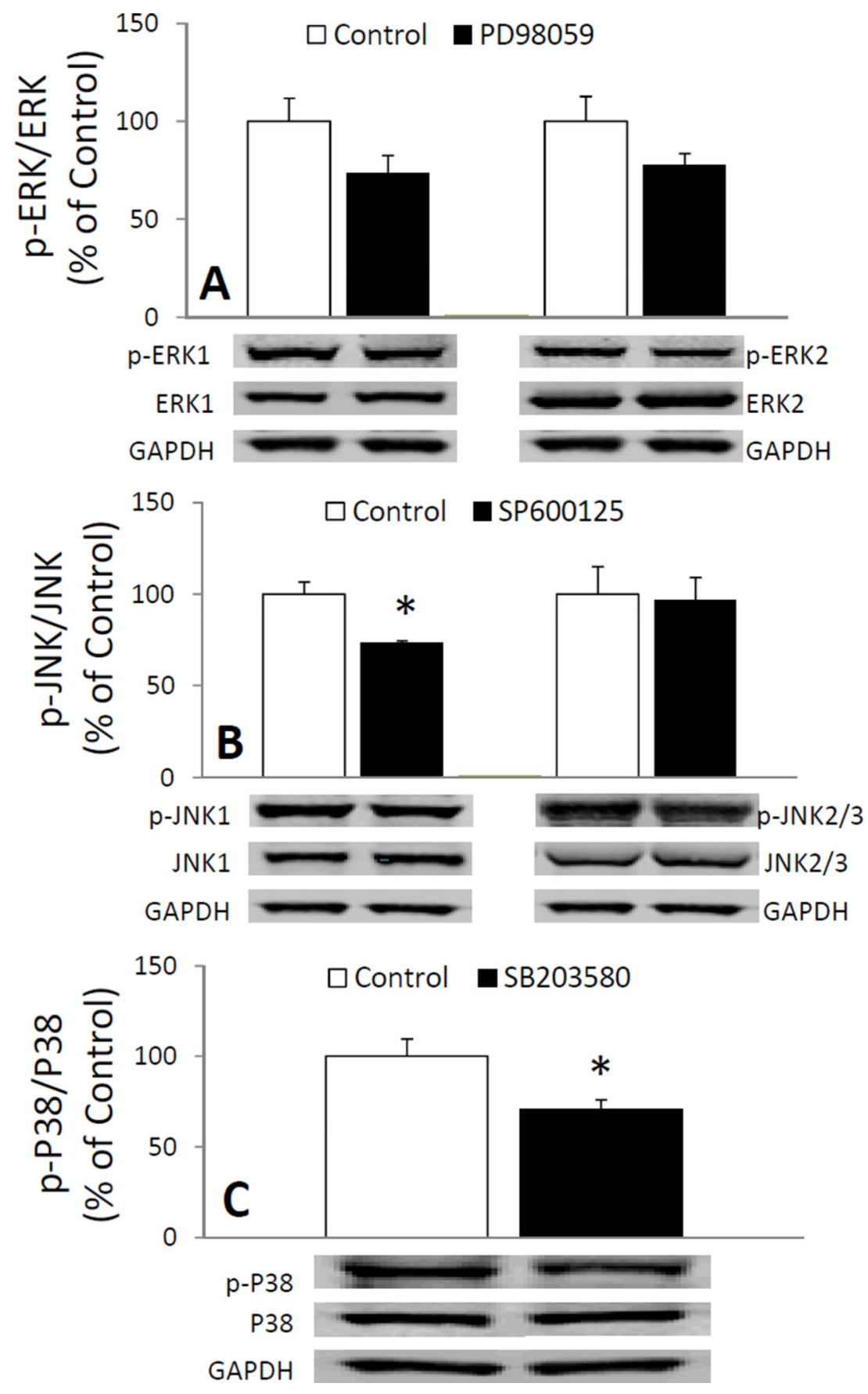

Figure 2.

Effect of pharmacologic inhibition of ERK1/2 (PD98059, $1 \mu \mathrm{g}$ ), JNK1/JNK2/3 (SP600125, $1 \mu \mathrm{g}$ ), and p38 (SB203580, $0.5 \mu \mathrm{g}$ ) on the expression of their respective proteins in the RVLM neurons. Illustrative gels depicting the expression of these proteins are shown. Values are means \pm S.E.M. of 5 observations. 

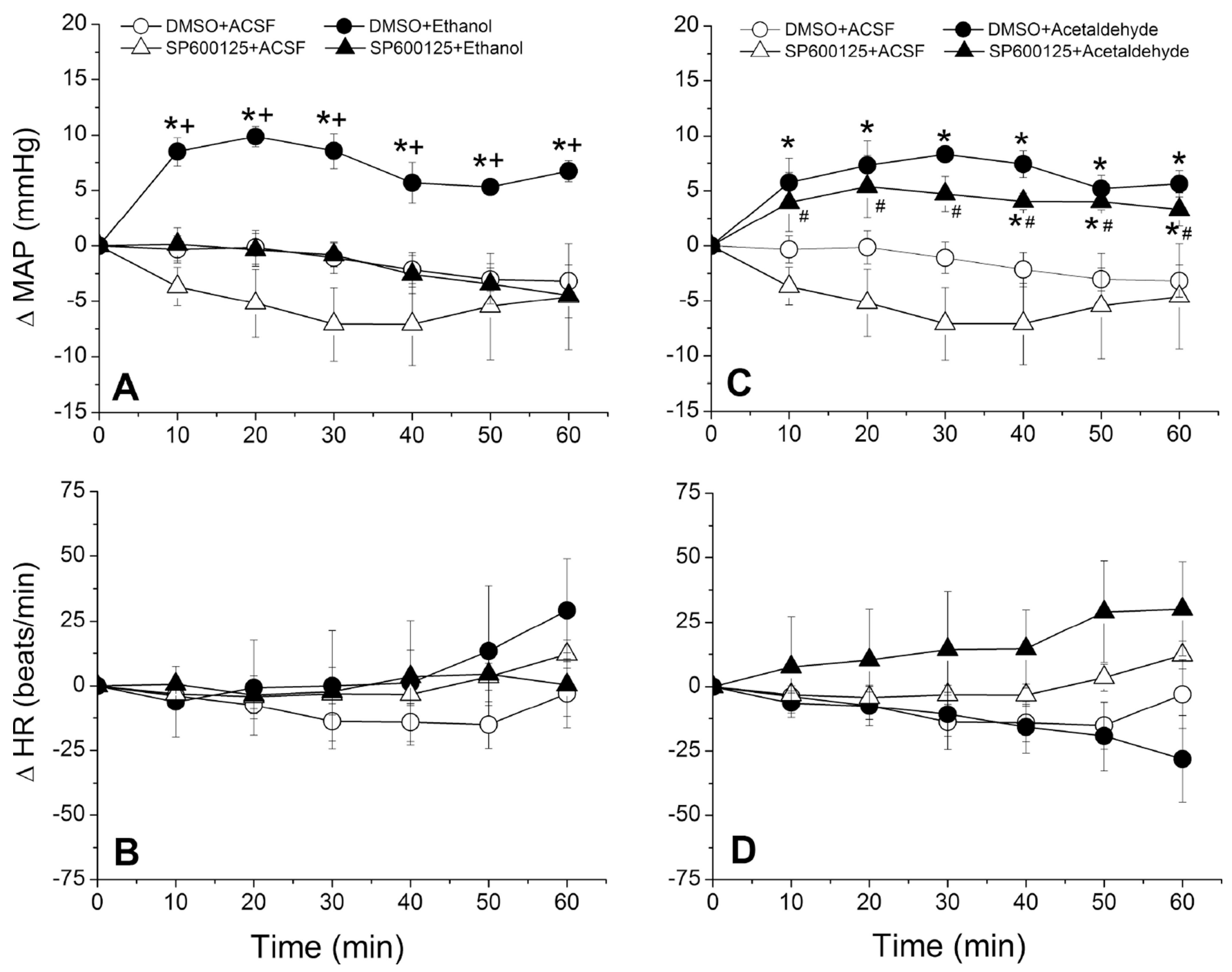

Figure 3.

Changes in mean arterial pressure ( $\triangle \mathrm{MAP})$ and heart rate $(\triangle \mathrm{HR})$ caused by intra-RVLM administration of ethanol (10 $\mu \mathrm{g}$, left panels), acetaldehyde ( $2 \mu \mathrm{g}$, right panels), or equal volume of ACSF $(80 \mathrm{nl})$ in conscious SHRs pretreated with the selective JNK inhibitor SP600125 $(1 \mu \mathrm{g})$ or its vehicle (DMSO). Values are means \pm S.E.M. of 6-7 observations. * $\mathrm{P}<0.05$ vs. respective "DMSO+ACSF" values, ${ }^{+} \mathrm{P}<0.05$ vs. respective "SP600125+ethanol" values, ${ }^{\text {P }}<0.05$ vs. respective "SP600125+ACSF" values. 

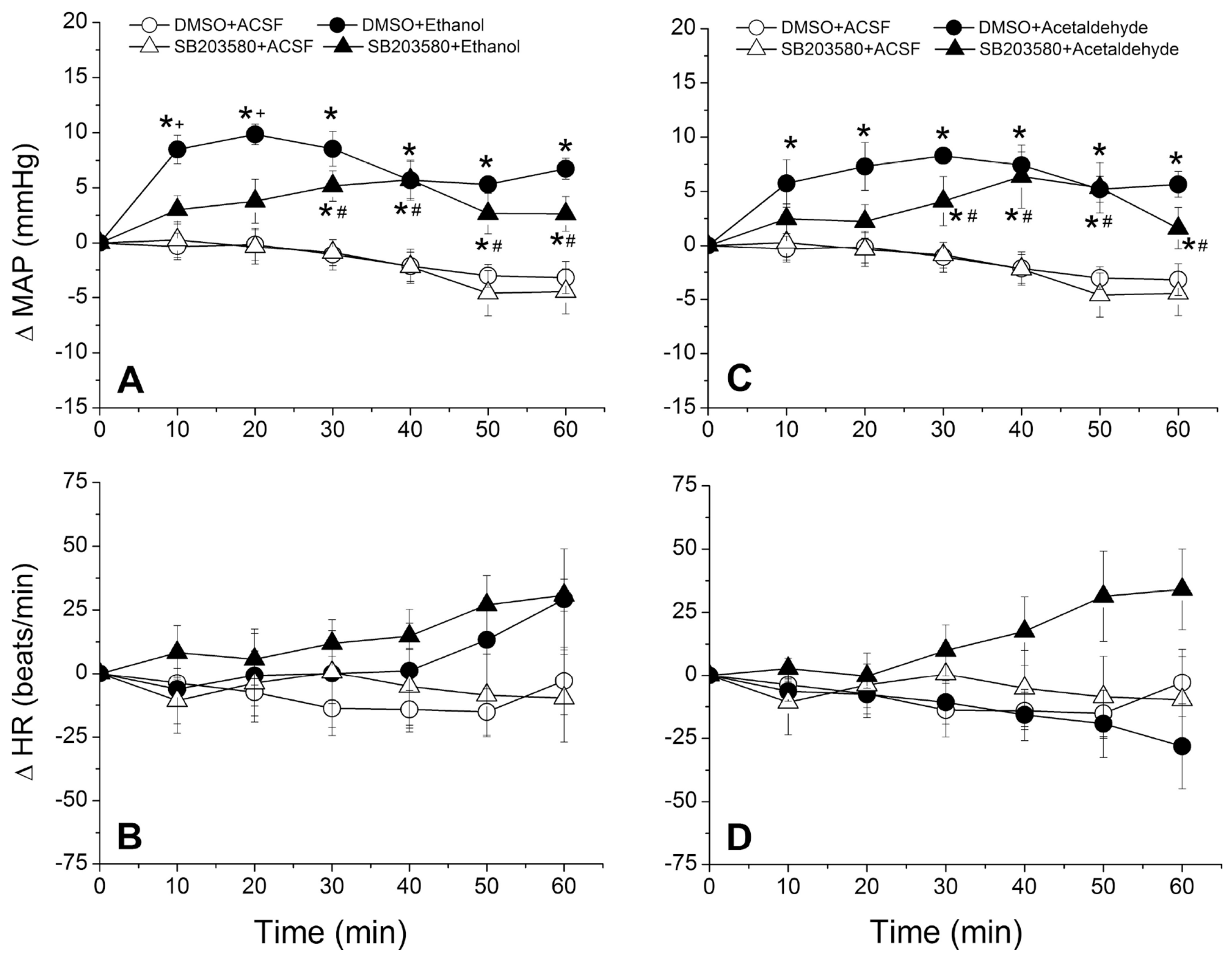

Figure 4.

Changes in mean arterial pressure $(\triangle \mathrm{MAP})$ and heart rate $(\triangle H R)$ caused by intra-RVLM administration of ethanol (10 $\mu \mathrm{g}$, left panels), acetaldehyde ( $2 \mu \mathrm{g}$, right panels), or equal volume of ACSF $(80 \mathrm{nl})$ in conscious SHRs pretreated with the selective p38 inhibitor SB203580 $(0.5 \mu \mathrm{g})$ or its vehicle (DMSO). Values are means \pm S.E.M. of 6-7 observations. ${ }^{*} \mathrm{P}<0.05$ vs. respective "DMSO+ACSF" values, ${ }^{+} \mathrm{P}<0.05$ vs. respective "SB203580+ethanol" values, ${ }^{\text {P }}<0.05$ vs. respective "SB203580+ACSF" values. 

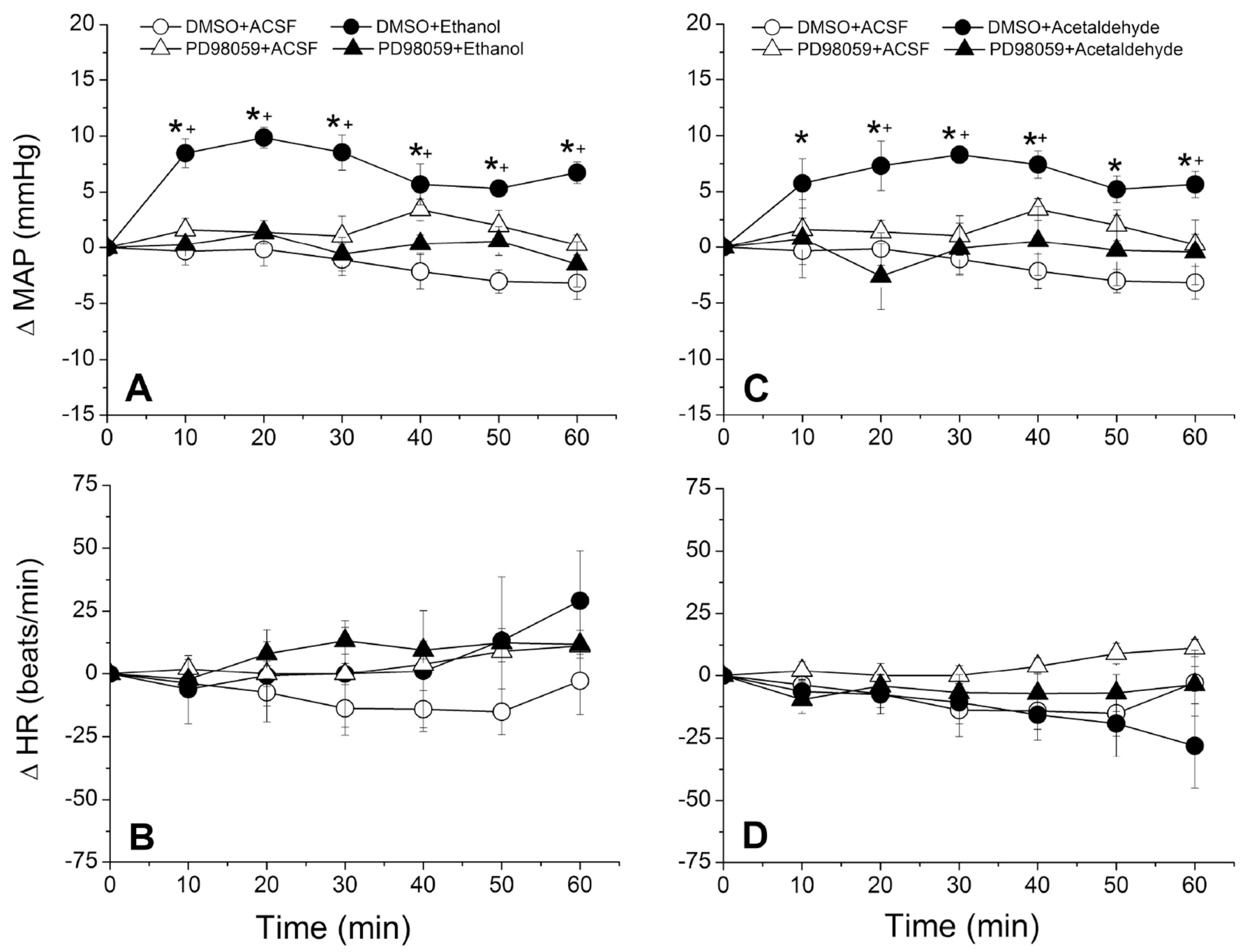

Figure 5.

Changes in mean arterial pressure ( $\triangle \mathrm{MAP})$ and heart rate $(\triangle H \mathrm{HR})$ caused by intra-RVLM administration of ethanol (10 $\mu \mathrm{g}$, left panels), acetaldehyde ( $2 \mu \mathrm{g}$, right panels), or equal volume of ACSF ( $80 \mathrm{nl}$ ) in conscious SHRs pretreated with the selective p44/42 inhibitor PD98059 $(1 \mu \mathrm{g})$ or its vehicle (DMSO). Values are means \pm S.E.M. of 6-7 observations. ${ }^{*} \mathrm{P}<0.05$ vs. respective "DMSO+ACSF" values, ${ }^{+} \mathrm{P}<0.05$ vs. respective "PD98059+ethanol" values. 

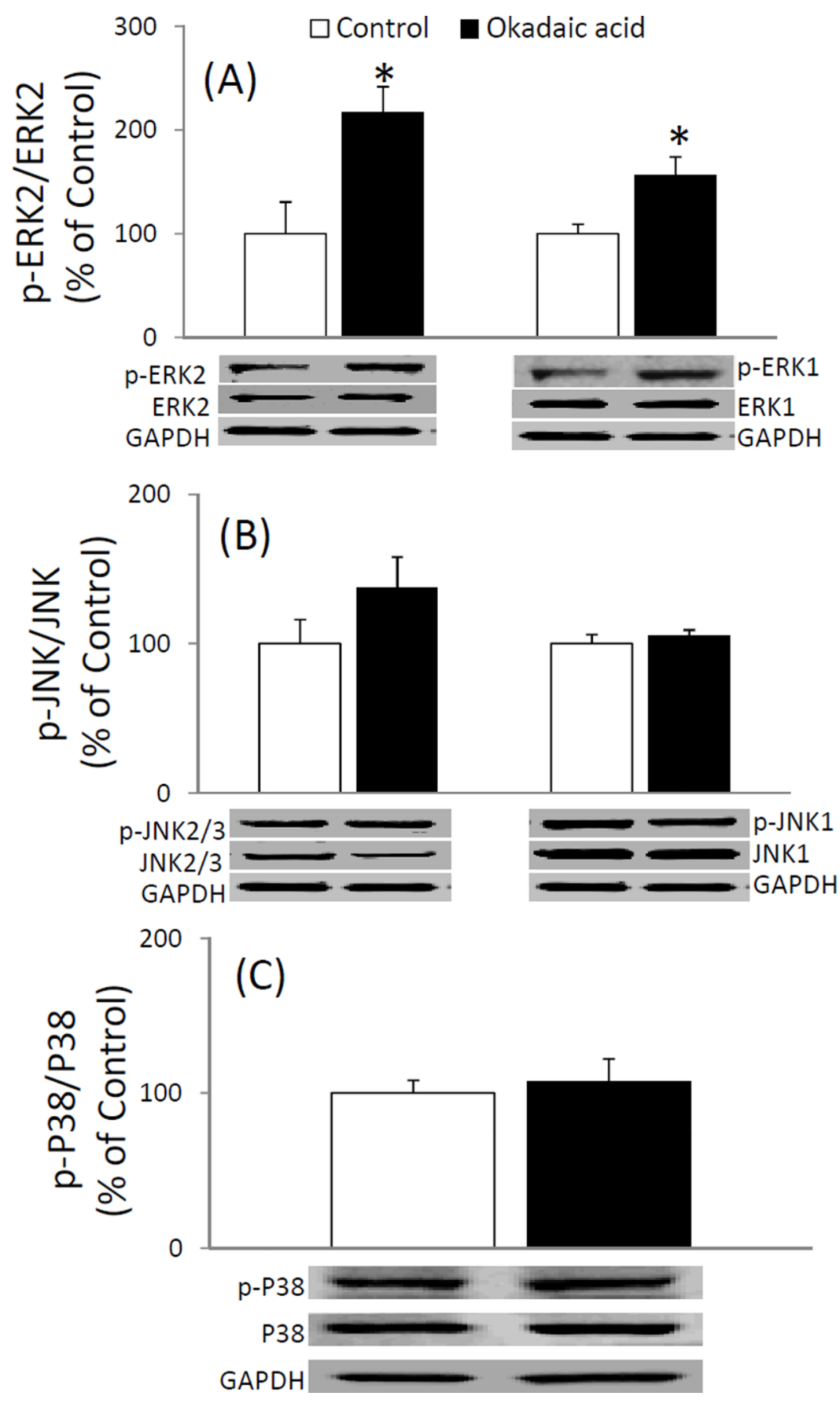

Figure 6.

The protein expressions of ERK1/2, JNK1/JNK2/3, and p38 in the RVLM of SHRs treated with okadaic acid $(0.4 \mu \mathrm{g})$ or equal volume of DMSO. Illustrative gels depicting the expression of these proteins are shown. Values are means \pm S.E.M of 6-8 observations. ${ }^{*} \mathrm{P}<0.05$ versus corresponding control (DMSO) values. 

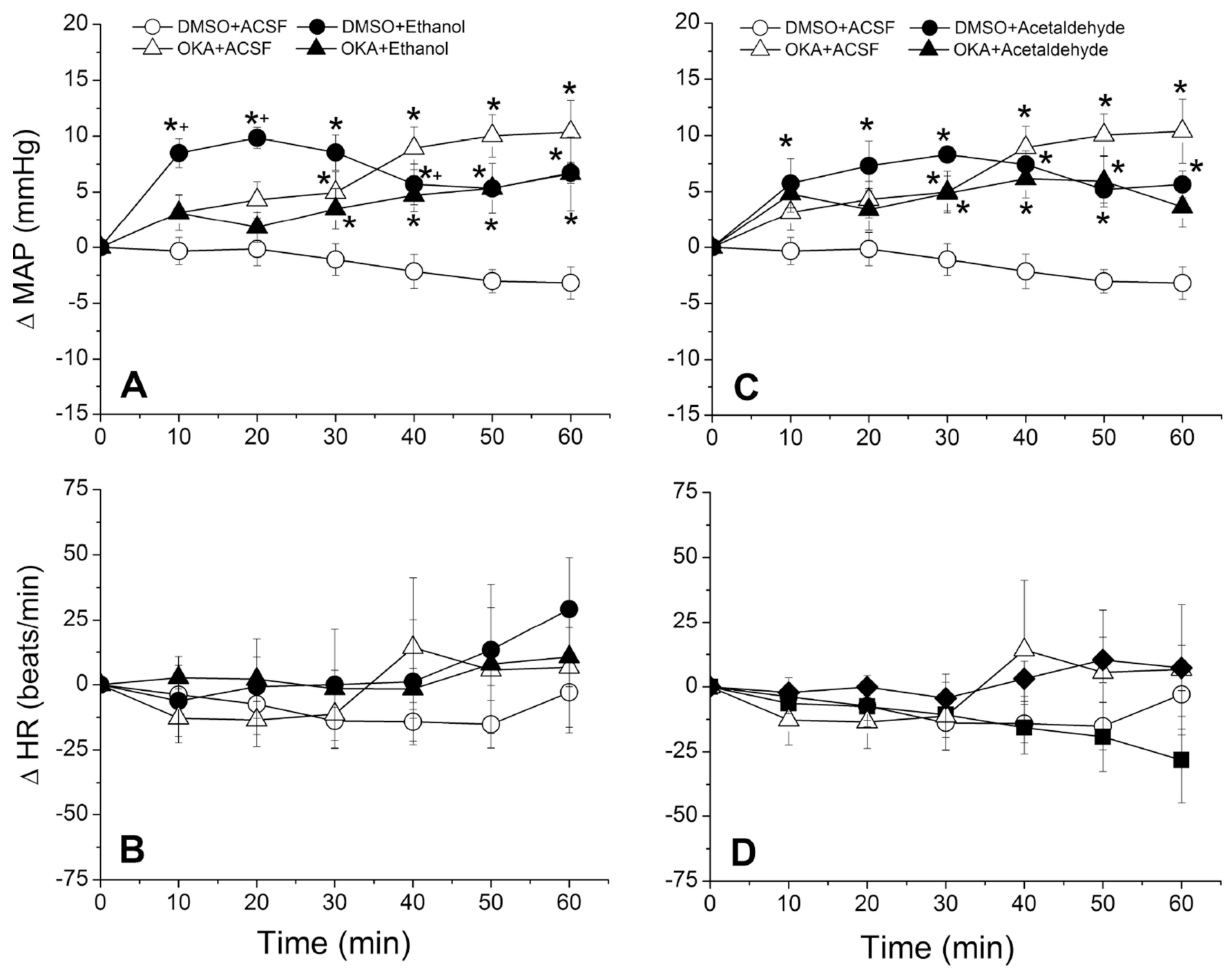

Figure 7.

Changes in mean arterial pressure $(\triangle \mathrm{MAP})$ and heart rate $(\triangle H R)$ caused by intra-RVLM administration of ethanol (10 $\mu \mathrm{g}$, left panels), acetaldehyde ( $2 \mu \mathrm{g}$, right panels), or equal volume of ACSF ( $80 \mathrm{nl}$ ) in conscious SHRs pretreated with the selective serine/threonine phosphatase inhibitor okadaic acid (OKA; $0.4 \mu \mathrm{g}$ ) or its vehicle (DMSO). Values are means \pm S.E.M. of $6-8$ observations. ${ }^{*} \mathrm{P}<0.05$ vs. respective "DMSO+ACSF" values, ${ }^{+} \mathrm{P}<0.05$ vs. respective "OKA+ethanol" values. 

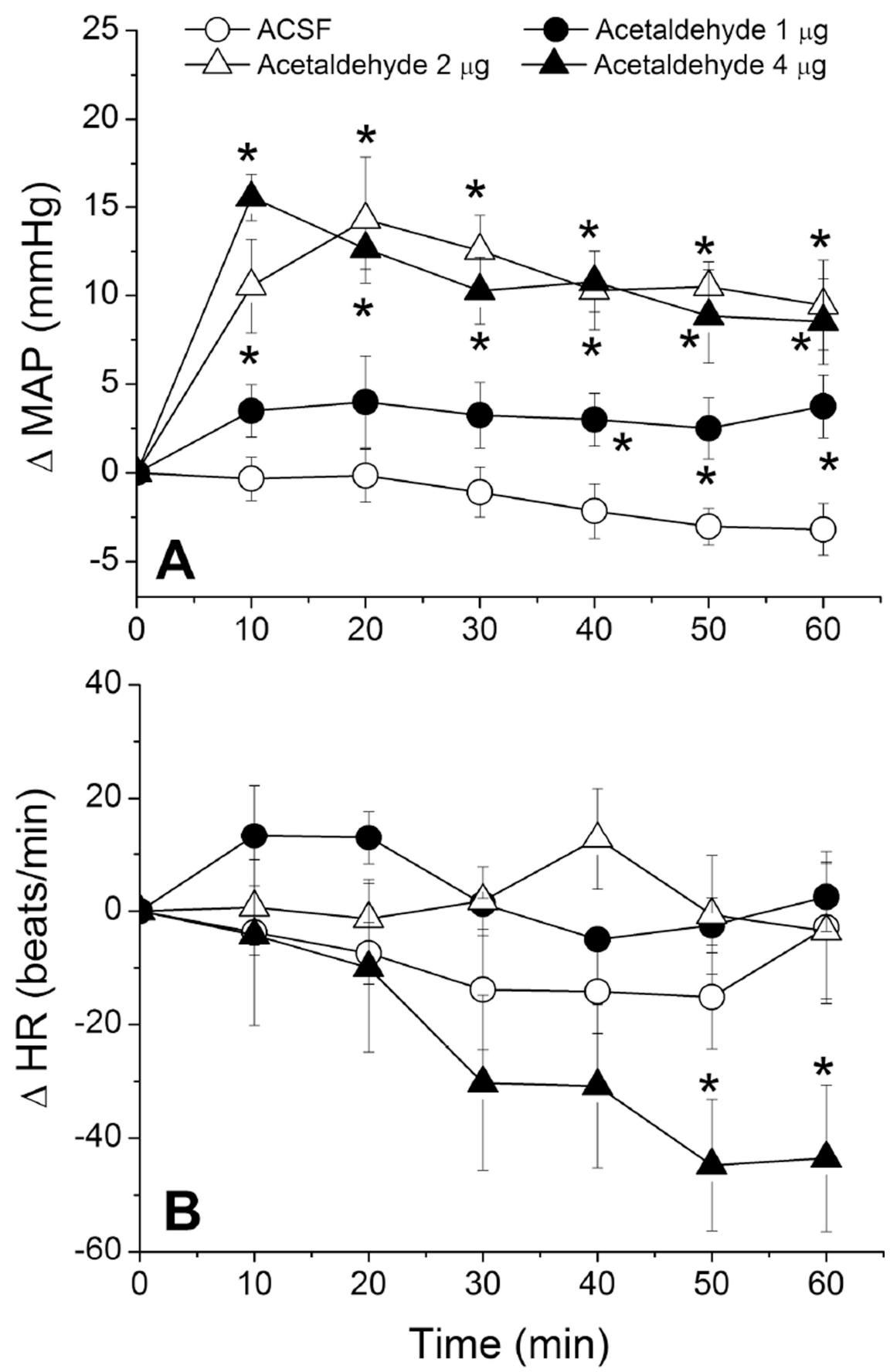

Figure 8.

Changes in mean arterial pressure $(\triangle \mathrm{MAP}$, panel $\mathrm{A})$ and heart rate $(\triangle \mathrm{HR}$, panel $\mathrm{B})$ caused by intra-RVLM administration of acetaldehyde $(1,2$, or $4 \mu \mathrm{g}$ ) or equal volume of ACSF (80 $\mathrm{nl}$ ) in conscious SHRs. Values are means \pm S.E.M. of $6-8$ observations. ${ }^{*} \mathrm{P}<0.05$ vs. respective ACSF values. 


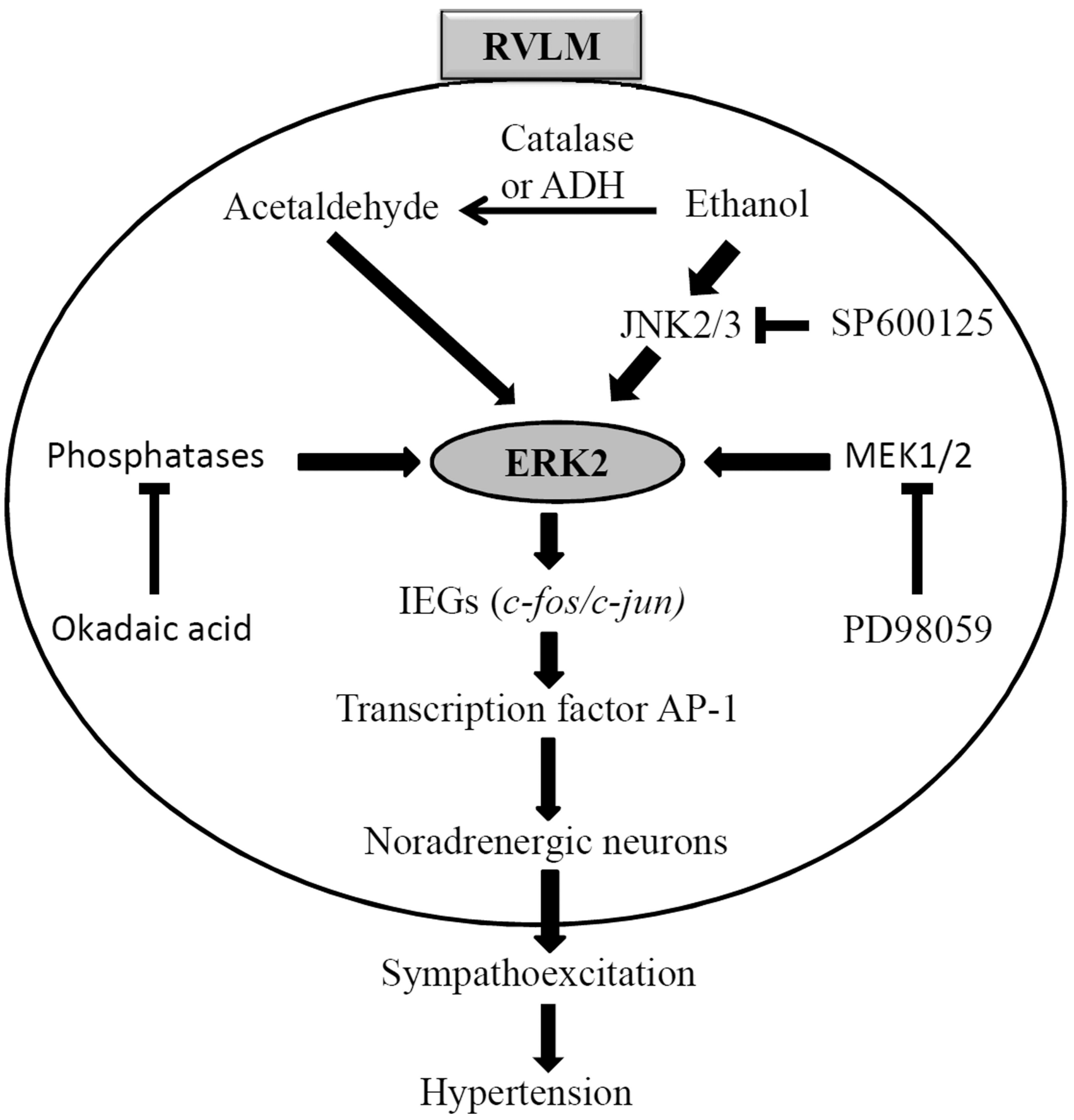

Figure 9.

Schematic illustration of the cascade of neuronal events that lead to the increase in central sympathetic outflow and subsequently the pressor response caused by intra-RVLM ethanol or acetaldehyde in SHRs. ADH, alcohol dehydrogenase; IEGs, immediate early genes; AP-1, activator protein-1; MEK1/2, mitogen-activated protein kinase kinase; pERK1/2, phosphorylated extracellular signal-regulated kinases. 


\section{Table 1}

Baseline values of mean arterial pressure (MAP, mmHg).

\begin{tabular}{lll}
\hline Group & n & MAP \\
\hline DMSO+ACSF & 6 & $177 \pm 8$ \\
DMSO+ethanol & 6 & $163 \pm 6$ \\
DMSO+acetaldehyde & 6 & $181 \pm 6$ \\
SP600125+ACSF & 6 & $169 \pm 3$ \\
SP600125+Ethanol & 6 & $171 \pm 3$ \\
SP600125+Acetaldehyde & 7 & $173 \pm 3$ \\
SB203580+ACSF & 6 & $165 \pm 3$ \\
SB203580+Ethanol & 7 & $174 \pm 3$ \\
SB203580+Acetaldehyde & 7 & $182 \pm 3$ \\
PD98059+ACSF & 6 & $181 \pm 6$ \\
PD98059+Ethanol & 6 & $179 \pm 8$ \\
PD98059+Acetaldehyde & 6 & $165 \pm 6$ \\
Okadaic acid+ACSF & 8 & $153 \pm 3$ \\
Okadaic acid+Ethanol & 7 & $169 \pm 3$ \\
Okadaic acid+Acetaldehyde & 7 & $165 \pm 3$ \\
\hline
\end{tabular}

Values are means \pm SEM. 